International Journal of Child, Youth and Family Studies (2017) 8(1): 112-144

DOI: http://dx.doi.org/10.18357/ijcyfs81201716944

\title{
CORRELATES OF BINGE DRINKING IN A SAMPLE OF CANADIAN UNIVERSITY STUDENTS
}

\section{Tamara Edkins, Jason D. Edgerton, and Lance W. Roberts}

\begin{abstract}
There is a lack of recent research exploring the differences between binge and non-binge drinkers among Canadian university students. The current study aims to address this gap in the literature through an exploratory statistical analysis. Univariate, bivariate, and multivariate (logistic regression) analyses were employed to identify the prevalence of binge drinking, as well as its various sociodemographic, behavioural, and mental health correlates. A large majority (83.1\%) of the 507 respondents reported consuming alcohol in the previous 12 months; of these, $69.7 \%$ (67.0\% of males, $70.9 \%$ of females) reported engaging in binge drinking ( 5 drinks in one session for males, 4 for females) at least once in the previous 30 days. Although there was no significant gender difference in the prevalence of binge drinking, there were several gender differences among the correlates. Compared to non-binge drinkers, male binge drinkers reported greater life satisfaction, and greater probability of smoking cigarettes and engaging in risky sex, while females reported greater impulsivity and lower religiosity. As expected, binge drinkers experienced more adverse consequences from alcohol consumption than did non-binge drinkers, but unexpectedly did not differ significantly in mental health and wellbeing. Limitations of the present study and future research directions are discussed with a view to improving our understanding of risk and protective factors related to unhealthy alcohol consumption among university students in Canada and abroad.
\end{abstract}

Keywords binge drinking; alcohol research; university students; Canada; mental health

Tamara Edkins MA is a student in the Faculty of Law at the University of Manitoba, 224 Dysart Rd., Winnipeg, MB R3T 2N2. Email: edkint@myumanitoba.ca

Jason D. Edgerton PhD (the corresponding author) is an Associate Professor in the Department of Sociology, 323 Isbister Building, 183 Dafoe Road, University of Manitoba, Winnipeg, MB R3T 2N2. Email: J.Edgerton@umanitoba.ca

Lance W. Roberts $\mathrm{PhD}$ is a Professor in the Department of Sociology at the University of Manitoba, 321 Isbister Building, 183 Dafoe Road, and a senior fellow at St. John’s College. Email: Lance.Roberts@umanitoba.ca 
International Journal of Child, Youth and Family Studies (2017) 8(1): 112-144

In the Canadian Community Health Survey, nearly 1 in 5 (17.9\%) Canadians aged 12 years or older (an estimated 5.3 million people) were classified as heavy drinkers (Statistics Canada, 2015). Past research has shown that Canadian university students tend to exhibit higher levels of heavy alcohol consumption than the general population (Adlaf, Demers, \& Gliksman, 2005; Arbour-Nicitopoulos, Kwan, Lowe, Taman, \& Faulkner, 2010; Kwan, Faulkner, ArbourNicitopoulos, \& Cairney, 2013). This trend has also been documented internationally, in countries such as Italy (DiGrande, Perrier, Lauro, \& Contu, 2000), Spain (Caamaño-Isorna, Corral, Parada, \& Cadaveira, 2008), the United Kingdom (Davoren, Demant, Shiely, \& Perry, 2016), France (Tavolacci et al., 2016), Sweden (Vaez \& Laflamme, 2003), New Zealand (Kypri et al., 2009), and, most extensively, in the United States (e.g. Fenzel, 2005; Jessor, Costa, Krueger, \& Turbin, 2006).

Binge drinking, or heavy episodic alcohol use, among university students appears to have become part of a "college culture”, in which consuming copious amounts of alcohol is increasingly normalized. For example, using a Canadian sample of university students, Arbour-Nicitopoulos et al. (2010) found that respondents overestimated by 30\%, on average, the percentage of students who had consumed alcohol in the past 30 days (e.g., alcohol was consumed by $65.8 \%$ of students, while participants estimated that $95.6 \%$ of students consumed alcohol), and that students who believed such consumption behaviour to be typical were approximately 7 times more likely to engage in such behaviour themselves. Although the prevalence of binge drinking among university students in Canada is not as severe as has been documented in the United States (Kuo et al., 2002), binge drinking has been associated with health issues, both mental and physical (Knight et al., 2002; Parada et al., 2012; Schoenborn, Stommel, \& Ward, 2014). For example, Knight et al. (2002) found that binge drinkers were 18 times more likely to be diagnosed with alcohol dependence, and 13 times more likely with alcohol abuse, than non-binge drinkers.

Numerous studies have highlighted the prevalence of binge drinking among university students; however, many Canadian studies used datasets that are now 10 or more - even up to 20 years old (e.g. Adlaf, Demers, \& Gliksman, 2005; Balodis et al., 2009; Gliksman, Newton-Taylor, Adlaf, \& Giesbrecht, 1997; Gliksman, Adlaf, Demers, \& Newton-Taylor, 2003), whereas other studies have simply focused on establishing the prevalence of alcohol use among Canadian university students (e.g. Arbour-Nicitopoulos et al., 2010; Kwan et al., 2013) rather than exploring bivariate or multivariate levels of analysis with regard to binge drinking. The most recent study exploring correlates of binge drinking among Canadian students (Carlson et al., 2010) focused on personality traits, not mental health. The current study attempts to address this gap in the Canadian literature by using more recent data (collected in 2014 and 2015) to compare binge versus nonbinge drinkers within a university sample using a logistic regression model. The current research is one of the only Canadian studies of university binge drinking to employ logistic regression (another was Gliksman et al., 2003), which enables the calculation of differences in the probability (and hence the risk) of binge drinking associated with particular student behaviours and attributes. 
International Journal of Child, Youth and Family Studies (2017) 8(1): 112-144

The theoretical background to this study is rooted in a developmental psychopathology perspective on emerging adulthood, one that focuses on the link between life transitions and health risks (Schulenberg \& Maggs, 2002; Schulenberg \& Zarrett, 2006). Such a perspective conceptualizes the transition to college as a critical period during which both developmental and contextual transitions can cause disruptive shifts in roles and expectations, heightened distress (Adlaf, Gliksman, Demers, \& Newton-Taylor, 2001) and increased vulnerability to disordered mental health (Conley, Kirsch, Dickson, \& Bryant, 2014). Emerging adulthood, as a time of increased autonomy, exploration, and experimentation, also leaves many university undergraduates vulnerable to excessive alcohol use (Arnett, 2005). Given previous evidence of the co-occurrence of alcohol and mental health disorders (e.g., Deykin, Levy, \& Wells, 1987; Swendsen et al., 1998), it is reasonable to expect that the transitional adjustment difficulties that are associated with increased probability of mental health issues might also be associated with increased probability of excessive alcohol use such as binge drinking. Thus, the overarching research questions guiding this study are: How prevalent is binge drinking in a sample of Canadian university students, and are there significant differences in a number of sociodemographic, attitudinal, behavioural, and mental health variables between binge drinkers and non-binge drinkers.

\section{Review of the Literature}

\section{Binge Drinking Operationalized}

Binge drinking has been defined in the literature as consuming five drinks or more in one sitting or outing (e.g., Gliksman et al., 2003; Jessor et al., 2006; Pascarella et al., 2007; Schaffer, Jeglic, \& Stanley, 2008). However, other researchers have elaborated upon this definition, and have further operationalized and supported the need to consider binge drinking as a gendered concept (e.g., Balodis et al., 2009; D’Alessio, Baiocco, \& Laghi, 2006; Delucchi, Matzger, \& Weisner, 2008; Simons, Christopher, \& Mclaury, 2004; Wechsler, Dowdall, Davenport, \& Rimm, 1995).

Based on arguments for gender differences in terms of body mass and weight (i.e., "gastric metabolism”; Wechsler et al., 1995, p. 982), most recent studies have conceptualized binge drinking as five or more drinks for males, and four or more drinks for females (or some similar adjustment). Such a gendered measure of binge drinking is consistent with the definition of binge drinking as suggested by the National Institute on Alcohol Abuse and Alcoholism (NIAAA; 2003), and has also been supported in the literature. For instance, Wechsler et al. (1995) conducted a study that compared binge drinking and alcohol-related consequences. The researchers found that females consuming four or more drinks were just as likely as men consuming five or more drinks to report adverse consequences from alcohol use, such as a hangover, missing class, falling behind in class, unplanned or unsafe sex, and related injuries. Females consuming five or more drinks were significantly more likely than males consuming the same amount to experience such adverse consequences. Therefore, in light of these gender-variant results, Wechsler and colleagues (1995) 
International Journal of Child, Youth and Family Studies (2017) 8(1): 112-144

argued that gendering the concept of binge drinking would provide a more meaningful threshold for alcohol abuse among females, because it takes into account the physical and metabolic differences between males and females. Similarly, others (e.g., DiGrande et al., 2000; Gliksman et al., 2003) have argued that using the five or more drinks measure for both men and women risks underestimating the prevalence of binge drinking among women. Accordingly, the present study will operationalize binge drinking as four drinks or more in one sitting for females and five drinks or more for males.

\section{Correlates of Binge Drinking}

The literature has identified numerous correlates of binge drinking (or heavy drinking) among university students and the general population, including demographic characteristics, personality traits, sexual behaviour, mental health, and further alcohol and drug use.

Gender: Gender is one of the key correlates of binge drinking among university students. Research, previous Canadian studies included, has consistently demonstrated that among university students, male students are more likely to engage in binge drinking compared to their female counterparts (e.g., Adlaf et al., 2005; Balodis et al., 2009; Carlson et al., 2010; Gliksman et al., 1997, 2003; Tavolacci et al., 2016).

Living Arrangements: Living arrangements have also been correlated with binge drinking among university or college students. The difference between students living with parents and students living away from parents has been noted in the literature. College students living on campus or away from their parents are typically more likely to engage in binge drinking than students living with their parents (Adlaf et al., 2005; Carlson et al., 2010; Gliksman et al., 1997, 2003; Tavolacci et al., 2016).

Canadian-born Status: There have been mixed results with regard to the relationship between immigrant status and binge drinking. Some research has found that Canadian newcomers are more likely to engage in high levels of alcohol consumption (Caetano, Clark, \& Tam, 1998), while other studies have found that Canadian-born respondents are more likely to engage in excessive alcohol use (Ross, 1995). However, few studies, and no recent ones, have explored this relationship in a Canadian university student population.

Family History of Alcohol Use: Alcohol abuse or problems with alcohol among college students (and the general population) have been associated with a family history of alcohol abuse (Meyerhoff et al., 2004; Perkins \& Berkowitz, 1991; Pullen, 1994; Weitzman, Nelson, \& Wechsler, 2003). In a study that defined binge drinking as consuming five or more drinks for males and four or more drinks for females at least once in the 2 weeks prior to being surveyed, Weitzman et al. (2003) found that of individuals who had begun binge drinking in college, 66\% indicated their parents drank, compared to $53 \%$ of individuals who did not begin to binge drink in college. Further, among a sample of American adults, Meyerhoff et al. (2004) reported that heavy drinkers (five drinks or more per day for males, and four drinks or more for females) were significantly 
more likely to report a family history of alcoholism compared to light drinkers (65\% vs. 42\%, respectively). However, despite such support in the literature for the association between a familial history of alcohol abuse and increased alcohol consumption, some research disputes the existence of such a relationship (e.g., Baer, 2002; Engs, 1990). Taken together, the results of existing research on the relationship between parental or family alcohol problems and heavy alcohol consumption are uncertain; therefore, more research is required to further examine any possible association, particularly in the Canadian context.

Grade Point Average (GPA): GPA and academic motivation of university students have been correlated with binge drinking, with students who engage in binge drinking reporting lower levels of academic achievement (Gilbert, 2014; Gliksman et al., 1997; Pascarella et al., 2007; Simons et al., 2004). For example, Simons and colleagues (2004) found that students who were engaged in higher academic achievement (“achievement strivings”) were more likely to report a lower number of binge drinking days. Further, Gliksman et al. (1997) found that students with an A average reported less propensity for engaging in heavy drinking (i.e., 15 or more drinks per week) compared to students with a GPA below A. Finally, Pascarella et al. (2007) found that students who engaged in binge drinking were more likely to have lower semester grades than nonbinge drinkers. This relationship held true even while controlling for numerous other demographics such as sex, race, and place of residence.

Mental Health: The co-occurrence of alcohol and mental health disorders has been established in the literature (e.g., Deykin et al., 1987; Swendsen et al., 1998); for example, Swendsen et al. found that respondents with alcoholism (i.e., alcohol abuse or dependence) were more likely to exhibit mental health issues such as anxiety or depression. Furthermore, mental health indicators such as depression, anxiety, quality of life, and positive/negative affect have been correlated with binge drinking or heavy alcohol consumption (Mohamed \& Ajmal, 2015; Mushquash et al., 2013; Powers, Duffy, Burns, \& Loxton, 2016; Townshend \& Duka, 2005). For example, Mushquash et al. (2013) found, among a Canadian sample of female university students, that heavy episodic drinking (having four or more drinks at a sitting) was associated with depression; by using longitudinal analysis, the researchers also found that depression significantly contributed to heavy episodic drinking, but not vice versa. Further, Mohamed and Ajmal (2015), using a sample of Irish adults, also found that binge drinkers were more likely to report lower scores on quality of life. Finally, Townshend and Duka (2005) reported that non-binge drinkers were more likely to report positive forms of affect (or a positive mood) compared to their binge drinking counterparts.

Other indicators of mental wellbeing such as social alienation and self-esteem have shown mixed results in the literature. In talking about social alienation, some studies have shown how people susceptible to peer pressure, and people with more friends, are more likely to engage in binge drinking (Talbott et al., 2008; Weitzman et al., 2003; Wechsler \& Kuo, 2000); however, other findings have indicated that individuals who report feelings of loneliness or fewer social interactions are more likely to engage in such behaviour (Knox, Vail-Smith, \& Zusman, 2007; 
Nezlek, Pilkington, \& Bilbro, 1994). No studies that we are aware of have explored the relationship between binge drinking and a validated or complete measure of social alienation among university students. Finally, contradictory results have been noted in the literature with regard to the relationship between self-esteem and heavy alcohol consumption among college students. For example, Jessor et al. (2006) found that low self-esteem acted as a risk factor for students who had low social support, while Valliant and Scanlan (1996) found that higher levels of alcohol consumption were associated with high levels of self-esteem, but neither Luhtanen and Crocker (2005) nor Poikolainen, Tuulio-Henriksson, Aalto-Setälä, Marttunen, and Lönnqvist (2001) found evidence of a significant relationship between self-esteem and binge drinking.

Religiosity: Religiosity, although less commonly explored than other factors in relation to binge drinking, has been associated with alcohol use in the literature. For instance, PatockPeckham, Hutchinson, Cheong, and Nagoshi (1998) found that students who identified as Catholic or Protestant were less likely to report engaging in alcohol use than students who identified as nonreligious. Further, Fenzel (2005), in a study of a sample of undergraduate students at a Catholic liberal arts college in the United States, found that strength of religious involvement was correlated with lower levels of heavy drinking (defined in their study as "consuming five or more drinks at a sitting over the previous two weeks”). Finally, Bock, Cochran, and Beeghley (1987) also found that religious involvement deterred heavy alcohol use among a sample of Americans (see also Galen \& Rogers, 2004; Wells, 2010). Although Hundleby (1987) and Rasic, Kisely, and Langille (2011) looked at the association between religiosity and alcohol use in Canadian adolescents, to our knowledge, there has to date been no investigation of such a relationship among Canadian university students.

Impulsivity: One personality trait that has been consistently correlated with binge drinking in the literature, especially among college students, is impulsivity (Balodis et al., 2009; Carlson et al., 2010; Caswell, Celio, Morgan, \& Duka, 2016; Clark et al., 2012; Townshend, Kambouropoulos, Griffin, Hunt, \& Milani, 2014; Wellman, Contreras, Dugas, O’Loughlin, \& O’Loughlin, 2014). In the literature, impulsivity is considered a multifaceted concept (as noted in Caswell et al., 2016); however, most commonly impulsivity refers to a deficits in the ability to regulate present actions and plan proactively, or to favouring spontaneous behaviour over regard for future consequences.

Researchers have noted the relationship between excessive alcohol consumption and heightened impulsivity. For example, in a United Kingdom study, Clark and colleagues (2012) found that among a mixed-gender sample of university students who were binge drinkers, the personality trait conscientiousness (which is inversely related to the trait impulsivity) decreased as the amount of alcohol consumed during the week increased. Further, Carlson et al. (2010) found that among Canadian male and female university students, binge drinking was positively associated with impulsivity, as well as with adventure seeking. Although there is thus some degree of consensus on the relationship between impulsivity and binge drinking, Balodis et al. (2009) found no difference in impulsivity between binge drinkers and non-binge drinkers; however, in 
the same study, the level of impulsivity was found to increase with the number of drinks consumed on a single occasion. Higher levels of alcohol consumption have been associated with diminution of neurological processes involved in "impulse control” (e.g., López-Caneda, Holguín, Corral, Doallo, \& Cadaveira, 2014); as argued by Henges and Marczinski (2012), individuals who cannot control the number of drinks they consume are the most at risk for binge drinking. Further, other studies have demonstrated that university students in peer groups who engage in peer delinquency such as stealing, smoking marijuana, or cheating on tests are more likely to also engage in binge drinking (Gibson, Schreck, \& Miller, 2004).

"Risky" Sexual Behaviour: Based on the association between binge drinking and disinhibition (or impulsivity), binge drinking has also been associated with risky sexual behaviour such as unprotected or unplanned sexual relations (Bersamin, Paschall, Saltz, \& Zamboanga, 2012; Brown \& Vanable, 2007; Connor, Psutka, Cousins, Gray, \& Kypri , 2013; Orchowski, Mastroleo, \& Borsari, 2012; Townshend et al., 2014). For example, Townshend et al. (2014), in comparing low-binge drinkers (those who scored lower than the median binge drinking score of 28.5 on the Alcohol Use Questionnaire which factors in both quantity and frequency) to high-binge drinkers (those who scored higher than the median score), found that high-binge drinkers reported more instances of unplanned sexual encounters than their lower-level counterparts. Further, Brown and Vanable (2007) reported that prior alcohol use before sexual relations was related to risky sexual behaviour (e.g., unprotected sex); however, this relationship existed more prominently among individuals engaging in sexual relations with non-steady partners. Finally, Orchowski et al. (2012) found that reporting higher levels of alcohol consumption per week and risky behaviours related to alcohol use were both significantly associated with reporting having had a sexual encounter under the influence of alcohol that was later regretted.

Alcohol and Drug Use: Binge drinking has also been associated with alcohol-related consequences and the age of onset of alcohol use, as well as illicit drug use and smoking tobacco cigarettes. For example, in one study students who engaged in binge drinking were more likely to report alcohol-related consequences such as physical injuries or alcohol dependence (Bennett, Miller, \& Woodall, 1999). Other studies have also found higher levels of alcohol-related consequences such as physical symptoms (e.g., hangover, insomnia, malnutrition); engaging in unlawful behaviour, interpersonal and intrapersonal problems (e.g., lower life satisfaction, lost friends); and academic consequences (e.g., missed classes, lower grades) to be associated with binge drinking (e.g., Carlson et al., 2010; Wechsler, Molnar, Davenport, \& Baer , 1999).

Binge drinking has also been associated with drug use, including tobacco cigarettes and marijuana. For instance, Bennett et al. (1999) found that a higher level of use of drugs (e.g., marijuana and other illegal drugs) was associated with higher levels of binge drinking. Further, DiGrande et al., (2000) found that university students who had recently used marijuana (in the previous 30 days) were an estimated 5 times more likely to engage in binge drinking, and students who had recently used cigarettes were 2.2 times more likely (see also Fenzel, 2005; Tavolacci et al., 2016; Townshend et al., 2014). 
International Journal of Child, Youth and Family Studies (2017) 8(1): 112-144

Age at first intoxication: Finally, the age at which students began drinking alcohol has also been associated with binge drinking among university students (Caamaño-Isorna et al., 2008; D’Alessio et al., 2006; Delucchi, Matzger, \& Weisner, 2008; DiGrande et al., 2000; Townshend et al., 2014; Weitzman et al., 2003). For example, Caamaño-Isorna et al. (2008) found that students who had engaged in alcohol use before they were 15 years old were 7.2 times more likely to engage in heavy episodic (binge) drinking. Further, DiGrande et al. (2000) found that students who began drinking alcohol before turning 17 were over 4 times more likely to engage in binge drinking than students who began drinking alcohol after 17 (42.2\% vs. 13.4\%, respectively). Finally, Townshend et al. (2014) found that high-level binge drinkers were more likely to have become intoxicated for the first time at an earlier age than low-level binge drinkers.

In sum, various sociodemographic, behavioural, and mental health variables have been examined for associations with binge drinking in general, and among university students in particular. However, not all correlates have been sufficiently or recently assessed among contemporary university students, especially in Canada. Accordingly, the present study will attempt to identify significant differences between binge drinkers and non-binge drinkers by examining these correlates using a current sample of Canadian university students.

\section{Methods}

\section{Data}

The current study ( $n=507)$ uses data from the Student Leisure and Well-Being Survey (SLWBS), which was administered in class to students enrolled in sections of either an Introduction to Sociology or an Introduction to Research Methods course at a midwestern urban Canadian university, the University of Manitoba in Winnipeg. The survey included questions about general demographics, mental health, personality, gambling behaviour, online gaming behaviour, and alcohol and drug use. Participation was voluntary, and the study was approved by the university’s Psychology/Sociology Research Ethics Board.

The SLWBS sample compares well to available institutional demographics for 2014 to 2015 (provided by the Office of Institutional Analysis at the university). The sample has slightly more female students (65.0\%) than are found in the university population overall (54.0\%). However, as noted in an institutional report on the Faculty of Arts, female university students were more likely than male students to be enrolled in sociology courses, and to major in sociology. A similar percentage of participants in the sample identified as full-time and part-time university students (82.6\% vs. 17.4\%), compared to the actual institutional distribution (88.4\% vs. 11.6\%). Further, the ratio of international to Canadian students (15.4\% vs. $84.6 \%$ ) is nearly identical to institutional demographics (15.1\% vs. 84.9\%). Finally, 88.7\% of participants were aged 18 to 24, which is comparable to the institutional proportion $(77.3 \%)$. In sum, the characteristics of the SLWBS sample appear reasonably representative of the general university population. 
International Journal of Child, Youth and Family Studies (2017) 8(1): 112-144

\section{Analytical Procedures}

All statistical analyses were conducted with SPSS 22. Univariate analysis was conducted first to assess the prevalence of binge drinking among Canadian university students. Then bivariate correlational analyses and multivariate logistic regression analyses were conducted separately for male and female subsamples. A logistic regression model requires a dichotomous dependent variable, and allows for continuous and categorical independent predictor variables (Tabachnick \& Fidell, 2013). The model was intended to explore which characteristics differentiate binge drinkers from non-binge drinkers in a sample of Canadian university students. Finally, an insignificant Little's MCAR test indicated that missing data were missing completely at random, but to preserve sample size and power, multiple imputation was used to generate 20 datasets from which final model estimates were pooled.

\section{Measures}

Binge Drinking: Based on the previously discussed literature (e.g., Wechsler et al., 1995), the current research project employed distinct thresholds for defining binge drinking for males and females. The dependent measure, binge drinking, was defined as consuming five or more alcoholic drinks in one session or sitting in the past 30 days for males, and consuming four or more drinks in the same period for females. Although there is a growing trend in the alcohol studies literature to replace the term "binge drinking" with the term "heavy episodic drinking”, the majority of the studies in our literature review refer to "binge drinking" as defined by the NIAAA (2004, p. 3); for consistency, we have therefore chosen to retain this term in the present discussion. A dichotomous variable was computed, with engaged in binge drinking behaviour coded as 1 .

Demographics: Several demographic variables were included in the following analysis: gender, immigrant status, family history of alcohol problems, living arrangements, and GPA. The majority of demographics were coded into dichotomous variables with being female, being born outside Canada, indicating a member of one's family has an alcohol problem, and living with parents each coded as 1. GPA was coded using the high school average for participants in their first year of university, and using university GPA for participants in their second year or beyond. GPA categories ranged from 4.0 to $4.5(\mathrm{~A} / \mathrm{A}+)$, 3.5 to $3.9(\mathrm{~B}+), 3.0$ to $3.4(\mathrm{~B}), 2.5$ to $2.9(\mathrm{C}+), 2.0$ to 2.4 (C), and 1.0 to 1.9 (D or lower). Notably, despite the importance of age in the literature (e.g., Gliksman et al., 1997; Perkins, 2007), it was not included in the current analysis due to lack of variation in the birth years of respondents. Sample demographics for binge drinkers and non-binge drinkers can be found in Table 1. 
International Journal of Child, Youth and Family Studies (2017) 8(1): 112-144

Table 1 Sample Description: Binge vs. Non-Binge Drinkers

\begin{tabular}{lll}
\hline Demographic Variable & Binge & Non-Binge \\
\hline Place of Birth & & \\
$\quad$ Canadian-born & $87.9 \%$ & $77.6 \%$ \\
$\quad$ Born outside of Canada & $12.1 \%$ & $22.4 \%$ \\
Student Status & & \\
$\quad$ Part-time & $10.8 \%$ & $12.1 \%$ \\
Full-time & $89.2 \%$ & $87.9 \%$ \\
First year of university complete & & \\
Yes & $42.1 \%$ & $49.3 \%$ \\
No & $57.9 \%$ & $50.7 \%$ \\
GPA (or High School Average) & & \\
4.0 to 4.5 (A/A+) & $30.6 \%$ & $26.4 \%$ \\
3.5 to 3.9 (B+) & $24.6 \%$ & $30.4 \%$ \\
3.0 to 3.4 (B) & $23.7 \%$ & $21.6 \%$ \\
2.5 to 2.9 (C+) & $13.9 \%$ & $11.5 \%$ \\
2.0 to 2.4 (C) & $5.6 \%$ & $6.1 \%$ \\
1.0 to 1.9 (D or lower) & $1.5 \%$ & $4.1 \%$ \\
Live with parents & & \\
Yes & $75.1 \%$ & $70.4 \%$ \\
No & $24.9 \%$ & $29.6 \%$ \\
Gender & & $38.2 \%$ \\
Male & $34.0 \%$ & $61.8 \%$ \\
Female & $66.0 \%$ & 1994 \\
Year of Birth (mean) & 1995 & \\
\hline
\end{tabular}

Mental Health: Measures of two mental health disorders, depression and anxiety, were included in the analysis. Anxiety was measured using the Generalized Anxiety Disorder 7-item (GAD-7) scale ( $\alpha=$.90; Spitzer, Kroenke, Williams, \& Löwe, 2006); depression was measured using the Center for Epidemiologic Studies Depression (CES-D) 20-item scale ( $\alpha=.91$; Eaton, Smith, Ybarra, Muntaner, \& Tien, 2004). Before computing the CES-D scale, four items had to be reverse coded. Finally, for both indices, high scores indicate high levels of mental illness ( $\min =$ 21, 55, respectively), while low scores indicate low levels of mental illness ( $\max =0$, for both).

Six measures of mental wellbeing were included in the analysis: positive affect, negative affect, life satisfaction, positive mental health, social alienation, and self-esteem. All variables were measured using indices that have been validated in the literature. Positive and negative affect ( $\alpha=.87, .82$, respectively) were measured using the short form of the Positive and Negative Affect Schedule (PANAS-SF; Ebesutani et al., 2012); life satisfaction was measured using the Diener's Satisfaction with Life Scale (SWLS; $\alpha=$.87; Diener, Emmons, Larsen, \& Griffin, 1985); positive mental health was measured using the Mental Health Continuum Short Form (MHC-SF; $\alpha=.92$; 
International Journal of Child, Youth and Family Studies (2017) 8(1): 112-144

Keyes, 2009); social alienation was measured using the Social Alienation Scale created by Jessor and Jessor (1977; $\alpha=.83$ ), where four positive-oriented or non-alienation items were reversecoded; and finally, self-esteem was measured using the Rosenberg Self-Esteem Scale (RSE; $\alpha=$ .89; Martin-Albo, Núñez, Navarro, \& Grijalvo, 2007), where five items were reverse-coded before computation.

Religiosity: Religiosity was measured using the Santa Clara Strength of Religious Faith (SCOSORF) questionnaire (Plante \& Boccaccini, 1997), a 10-item index measuring the level of religious faith among respondents $(\alpha=.98)$. The measure ranged from 0 to 30, with 30 indicating the strongest level of religiosity.

Impulsivity: Impulsivity was measured using the Barratt Impulsiveness Scale (BIS-11), a 26-item index that has been used to measure impulsivity among university students in previous studies (Stanford et al., 2009). The index was computed by adding the 26 items together $(\alpha=.82)$. Before computation 11 of the items were reverse-coded. High scores on the index indicate high levels of impulsivity ( $\max =62)$, while low scores indicate low levels of impulsivity $(\min =3)$.

“Risky” Sexual Behaviour: Risky sexual behaviour was computed by combining two variables, measures of unprotected and unplanned sexual relations $(\alpha=.71)$. Respondents were asked whether, in the past 12 months, they had, while under the influence of alcohol, engaged in (a) unplanned sex or (b) unprotected sex with a person they had never met before. The risky sexual behaviour variable was coded into a dichotomous variable, with those answering "yes" to one or both of the risky sexual behaviour items receiving a score of 1 and those answering "no" to both measures receiving a score of 0 .

Experiences with Drugs and Alcohol: A number of variables were used to measure experiences with drugs and alcohol. The validated shorter 18-item version of Rutgers Alcohol Problem Index (RAPI) was used to measure the number of alcohol-related consequences $(\alpha=.88$; White \& Labouvie, 2000). Due to excessive kurtosis and skewness, the natural log of the RAPI score was used. Early experiences with alcohol were measured using one variable: the age at which one first became intoxicated from alcohol. Drug use was measured by two dichotomous variables: tobacco cigarette use (“yes” =1) and use of other drugs including marijuana, heroin, and cocaine (use of one or more $=1$ ).

\section{Results}

\section{Univariate Analysis: Prevalence of Binge Drinking}

In the current study, $83.1 \%$ of respondents reported consuming alcohol in the past 12 months; $69.7 \%$ of these students reported engaging in binge drinking at least once in the previous 30 days. There was no significant difference between the proportion of males (67.0\%) and females (70.9\%) who indicated binge drinking $\left(\chi^{2}=.798, p=.372\right)$. 
International Journal of Child, Youth and Family Studies (2017) 8(1): 112-144

For students who had engaged in binge drinking, the most common reported frequency was 2 to 3 times in the previous 30 days (42.8\%), followed by 1 time in the previous 30 days (35.9\%), 1 to 2 times per week (15.5\%), 3 to 4 times per week (1.4\%), and more than 5 times per week (3.7\%). Descriptive statistics for modelled predictor variables are reported in Table 2 for the overall sample, and for the male and female subsamples.

Table 2 Descriptive Statistics

\begin{tabular}{lccc}
\hline Predictor Variable & \multicolumn{1}{c}{ Overall } & Male & Female \\
\hline Continuous measures & \multicolumn{3}{c}{ Mean (Standard Deviation) } \\
\cline { 2 - 4 } Religiosity & $10.13(10.13)$ & $9.79(9.96)$ & $11.65(10.18)$ \\
Impulsivity & $32.62(10.20)$ & $33.03(10.24)$ & $32.43(10.18)$ \\
RAPI (logged) & $.439(.432)$ & $.459(.447)$ & $.430(.424)$ \\
Age at first intoxication & $16.05(2.22)$ & $16.17(2.56)$ & $15.99(2.02)$ \\
Depression & $17.93(10.8)$ & $16.55(10.500$ & $18.71(10.90)$ \\
Anxiety & $8.91(5.51)$ & $7.78(5.25)$ & $9.51(5.55)$ \\
Life satisfaction & $11.94 \mathrm{~b}(4.26)$ & $12.20(4.08)$ & $11.80(4.33)$ \\
Positive mental health & $47.27(12.24)$ & $48.12(11.74)$ & $46.82(12.44)$ \\
Positive affect & $12.59(3.56)$ & $12.88(3.63)$ & $12.45(.38)$ \\
Negative affect & $6.68(3.42)$ & $6.10(3.46)$ & $6.99(3.34)$ \\
Social alienation & $25.38(9.04)$ & $24.58(8.93)$ & $25.84(9.08)$ \\
Self-esteem & $19.49(5.55)$ & $20.43(5.52)$ & $18.97(5.51)$ \\
Categorical measures & & & \\
Binge drink & & $\%$ Yes & \\
Live with parents & 69.7 & 67.0 & 70.9 \\
Born outside Canada & 69.6 & 69.4 & 69.7 \\
Risky sexual behaviour & 22.7 & 25.3 & 21.0 \\
Cigarette use & 12.2 & 18.6 & 8.8 \\
Other drug use & 20.8 & 22.2 & 20.2 \\
Family history of alcohol problems & 34.6 & 34.6 & 34.7 \\
GPA (or high school average) & 45.0 & 42.2 & 47.3 \\
4.0 to 4.5 (A+/A) & & & \\
3.5 to 3.9 (B+) & 27.8 & 24.9 & 29.3 \\
3.0 to 3.4 (B) & 25.3 & 24.9 & 25.4 \\
2.5 to 2.9 (C+) & 21.6 & 21.3 & 21.8 \\
$\quad$ 2.0 to 2.4 (C) & 16.3 & 16.9 & 16.1 \\
$\quad$ 1.0 to 1.9 (D or lower) & 5.9 & 8.2 & 4.7 \\
\hline
\end{tabular}


International Journal of Child, Youth and Family Studies (2017) 8(1): 112-144

\section{Bivariate Analysis: Correlates of Binge Drinking}

Correlations for each gender sample are reported in Tables 3 and 4. Illicit drug use, cigarette smoking, and reporting negative consequences from use of alcohol were positively correlated with binge drinking for both sexes, while age at first consumption or intoxication was negatively correlated with binge drinking for both sexes. Strength of religious faith was negatively correlated with binge drinking for females but not for males, while impulsivity was positively correlated with binge drinking for females but not for males. Anxiety, depression, and being born outside Canada were negatively associated with binge drinking for males, but not for females, while life satisfaction and having engaged in risky sex were positively correlated with binge drinking for males but not females. Neither positive or negative affect, nor positive mental health, alienation, or self-esteem were significantly correlated with binge drinking for either gender. None of the remaining sociodemographic variables — residing with parents (or not), GPA, having family members with alcohol problems - were significantly correlated with binge drinking for males or females. 
International Journal of Child, Youth and Family Studies (2017) 8(1): 112-144

Table 3 Female Sample Correlations

\begin{tabular}{|c|c|c|c|c|c|c|c|c|c|c|c|c|c|c|c|c|c|c|c|c|}
\hline Var. & 1 & 2 & 3 & 4 & 5 & 6 & 7 & 8 & 9 & 10 & 11 & 12 & 13 & 14 & 15 & 16 & 17 & 18 & 19 & 20 \\
\hline 1 & - & & & & & & & & & & & & & & & & & & & \\
\hline 2 & .084 & - & & & & & & & & & & & & & & & & & & \\
\hline 3 & .009 & $.137 * *$ & - & & & & & & & & & & & & & & & & & \\
\hline 4 & -.091 & -.020 & $-.144 * *$ & - & & & & & & & & & & & & & & & & \\
\hline 5 & .076 & $.045^{* *}$ & $.055^{* *}$ & $-.092 * *$ & - & & & & & & & & & & & & & & & \\
\hline 6 & $.242 * *$ & $-.036 * *$ & $-.231^{* *}$ & $-.090 * *$ & $.133^{* *}$ & - & & & & & & & & & & & & & & \\
\hline 7 & $.193 * *$ & .003 & $-.055^{* *}$ & $-.088 * *$ & $.094 * *$ & $.449 * *$ & - & & & & & & & & & & & & & \\
\hline 8 & $.227 * *$ & $.032 * *$ & -.012 & $-.098 * *$ & $.266 * *$ & $.439 * *$ & $.395 * *$ & - & & & & & & & & & & & & \\
\hline 9 & $-.140^{*}$ & $-.034 * *$ & $.035 * *$ & $.094 * *$ & $-.221 * *$ & $-.347^{* *}$ & $-.302 * *$ & $-.248^{* * *}$ & - & & & & & & & & & & & \\
\hline 10 & $-.213^{* *}$ & .008 & $-.054 * *$ & $.244 * *$ & $-.130 * *$ & $-.282 * *$ & $-.150 * *$ & $-.163 * *$ & $.166^{* *}$ & - & & & & & & & & & & \\
\hline 11 & $.207 * *$ & $.049 * *$ & $-.172^{* *}$ & $.072 * *$ & $.138 * *$ & $.246^{* *}$ & $.215^{* *}$ & $.272^{* *}$ & $-.236 * *$ & $-.066 * *$ & - & & & & & & & & & \\
\hline 12 & .018 & $-.024 *$ & $.179^{* *}$ & $-.167 * *$ & $-.022 *$ & $-.171^{* *}$ & $-.108 * *$ & $-.124 * *$ & $-.065^{* *}$ & $.125^{* *}$ & $.269 * *$ & - & & & & & & & & \\
\hline 13 & .056 & $.083^{* *}$ & $-.118 * *$ & $.060^{* *}$ & $.116^{* *}$ & $.199 * *$ & $.181^{* *}$ & $.237 * *$ & $-.050 * *$ & $-.124^{* *}$ & $.352 * *$ & $-.575^{* *}$ & - & & & & & & & \\
\hline 14 & .073 & $.110^{* *}$ & -.001 & $-.057 * *$ & $.087^{* *}$ & $.192 * *$ & $.187^{* *}$ & $.256 * *$ & $-.062 * *$ & $-.081^{* *}$ & $.200 * *$ & $-.331^{* *}$ & $.673^{* *}$ & - & & & & & & \\
\hline 15 & -.010 & $-.125^{* *}$ & $-.058 * *$ & $-.134 * *$ & $.050^{* *}$ & $.095^{* *}$ & $.123^{* *}$ & $.144 * *$ & $-.069 * *$ & $-.104^{* *}$ & $.066 * *$ & $-.133^{* *}$ & $.086^{* *}$ & $.061^{* *}$ & - & & & & & \\
\hline 16 & -.018 & $.040^{* *}$ & $-.156^{* *}$ & $.040^{* *}$ & $.068 * *$ & $.130 * *$ & $.056^{* *}$ & $.125^{* *}$ & $-.029 * *$ & $-.116^{* *}$ & $.370^{* *}$ & $-.566^{* *}$ & $.625^{* *}$ & $.407 * *$ & $.163^{* *}$ & - & & & & \\
\hline 17 & -.029 & $-.054^{* *}$ & $.087^{* *}$ & $-.052 * *$ & $-.070^{* *}$ & $-.213^{* *}$ & $-.178 * *$ & $-.175^{* *}$ & $.031 * *$ & $.192^{* *}$ & $-.338^{* *}$ & $.632 * *$ & $-.703^{* *}$ & $-.508 * *$ & $-.099 * *$ & $-.713^{* *}$ & - & & & \\
\hline 18 & .083 & $.032 * *$ & $-.103^{* *}$ & $.108 * *$ & $.132^{* *}$ & $.169 * *$ & $.162^{* *}$ & $.206^{* *}$ & $.071^{* *}$ & $-.083 * *$ & $.307 * *$ & $-.513^{* *}$ & $.716^{* *}$ & $.534^{* *}$ & $.072^{* *}$ & $.480^{* *}$ & $-.587 * *$ & - & & \\
\hline 19 & .051 & $-.029^{*}$ & $.023^{*}$ & $-.079 * *$ & .015 & -.017 & .004 & $-.119 * *$ & $-.039 * *$ & $.060^{* *}$ & $-.197 * *$ & $.580 * *$ & $-.634 * *$ & $-.364 * *$ & $-.077 * *$ & $-.554^{* *}$ & $.587 * *$ & $-.525 * *$ & - & \\
\hline 20 & .013 & -.013 & .130 ** & $-.082 * *$ & $.031 * *$ & $-.077^{* *}$ & $-.079 * *$ & $-.146^{* *}$ & -.016 & $.065 * *$ & $-.325^{* *}$ & $.609 * *$ & $-.654 * *$ & $-.373^{* *}$ & $-.111^{* *}$ & $-.612 * *$ & $.663^{* *}$ & $-.526 * *$ & $.791^{* *}$ & - \\
\hline
\end{tabular}

Notes: 1=Binge drinking; 2=Live with parents; 3=GPA; 4=Born outside Canada; 5=Risky sex; 6=Drug use; 7=Cigarette use; 8=RAPI; 9=Age at first intoxication; 10=Religiosity; 11=Impulsivity;

12=Life satisfaction; 13=Depression; 14=Anxiety; 15=Family alcohol problems; 16=Social alienation; 17=Self-esteem; 18=Negative affect; 19=Positive affect; 20=Positive mental health

${ }^{*} \mathrm{p} \leq .05, * * \mathrm{p} \leq .01$

Table 4 Male Sample Correlations

\begin{tabular}{|c|c|c|c|c|c|c|c|c|c|c|c|c|c|c|c|c|c|c|c|c|}
\hline Var. & 1 & 2 & 3 & 4 & 5 & 6 & 7 & 8 & 9 & 10 & 11 & 12 & 13 & 14 & 15 & 16 & 17 & 18 & 19 & 20 \\
\hline 1 & - & & & & & & & & & & & & & & & & & & & \\
\hline 2 & .026 & - & & & & & & & & & & & & & & & & & & \\
\hline 3 & .114 & $.166^{* *}$ & - & & & & & & & & & & & & & & & & & \\
\hline 4 & $-.250 * *$ & $-.172 * *$ & $-.086 * *$ & - & & & & & & & & & & & & & & & & \\
\hline 5 & $.319 * *$ & $-.037 *$ & $-.107 * *$ & $-.121^{* *}$ & - & & & & & & & & & & & & & & & \\
\hline 6 & $.156^{* *}$ & $.029 *$ & $-.068 * *$ & $-.208 * *$ & $.330 * *$ & - & & & & & & & & & & & & & & \\
\hline 7 & $.238 * *$ & .001 & $-.115^{* *}$ & $-.137 * *$ & $.212^{* *}$ & $.423 * *$ & - & & & & & & & & & & & & & \\
\hline 8 & $.200 *$ & $.029 *$ & $-.075^{* *}$ & $-.046 * *$ & $.348 * *$ & $.350 * *$ & $.420 * *$ & - & & & & & & & & & & & & \\
\hline 9 & $-.158 *$ & $-.039 * *$ & .023 & $.311^{* *}$ & $-.205^{* *}$ & $-.290 * *$ & $-.279 * *$ & $-.224 * *$ & - & & & & & & & & & & & \\
\hline 10 & -.088 & $.078^{* *}$ & $.032 *$ & $.292 * *$ & $-.119 * *$ & $-.240 * *$ & $-.132 * *$ & $-.081^{* *}$ & $.256 * *$ & - & & & & & & & & & & \\
\hline 11 & .074 & $-.057 * *$ & $-.200 * *$ & $.064 * *$ & $.213^{* *}$ & $.098 * *$ & $.136^{* *}$ & $.381^{* *}$ & $-.092 * *$ & $-.033^{*}$ & - & & & & & & & & & \\
\hline 12 & $.236 * *$ & $.089 * *$ & $.235^{* *}$ & $-.182 * *$ & $.076^{* *}$ & -.025 & -.020 & $-.046 * *$ & $-.164^{* *}$ & $-.100 * *$ & $-.186 * *$ & - & & & & & & & & \\
\hline 13 & $-.188^{*}$ & $-.070 * *$ & $-.167 * *$ & $.153^{* *}$ & $.038 *$ & .017 & $.093 * *$ & $.244^{* *}$ & $.113^{* *}$ & $.124^{* *}$ & $.350 * *$ & $-.554 * *$ & - & & & & & & & \\
\hline 14 & $-.151^{*}$ & .000 & $-.143 * *$ & $.050 * *$ & .016 & -.008 & $.129 * *$ & $.198^{* *}$ & $.090 * *$ & $.115^{* *}$ & $.264 * *$ & $-.406 * *$ & $.738 * *$ & - & & & & & & \\
\hline 15 & .138 & $-.098 * *$ & .009 & $-.188 * *$ & $-.040 *$ & $.050 * *$ & $.186 * *$ & $.249 * *$ & $-.082 * *$ & $-.117 * *$ & $.095 * *$ & $-.122 * *$ & $.081^{* *}$ & $.122 * *$ & - & & & & & \\
\hline 16 & .097 & $.062 * *$ & $-.075^{* *}$ & $.089 * *$ & -.023 & -.016 & $.065^{* *}$ & $.195^{* *}$ & $-.081^{* *}$ & $.140 * *$ & $.321 * *$ & $-.475 * *$ & $.626 * *$ & $.525^{* *}$ & $.092 * *$ & - & & & & \\
\hline 17 & .193 & -.013 & $.240 * *$ & $-.198 * *$ & $.040 * *$ & -.007 & $-.077 * *$ & $-.203 * *$ & $-.133 * *$ & $-.124 * *$ & $-.371^{* *}$ & $.645^{* *}$ & $-.729 * *$ & $-.634^{* *}$ & $-.110 * *$ & $-.639 * *$ & - & & & \\
\hline 18 & -.178 & .013 & $-.056^{* *}$ & $.131^{* *}$ & $-.051^{* *}$ & -.027 & .000 & $.175^{* *}$ & $.216^{* *}$ & $.143^{* *}$ & $.245^{* *}$ & $-.377 * *$ & $.642 * *$ & $.718^{* *}$ & $.118^{* *}$ & $.392^{* *}$ & $-.582 * *$ & - & & \\
\hline 19 & .117 & $.105^{* *}$ & $.190 * *$ & $-.069 * *$ & $.063 * *$ & $.039 *$ & -.021 & $-.064 * *$ & $-.054 * *$ & $-.043 * *$ & $-.209 * *$ & $.598 * *$ & $-.516 * *$ &,$- 359 * *$ & $-.181^{* *}$ & $-.443 * *$ & $.621^{* *}$ & $-.376^{* *}$ & - & \\
\hline 20 & .140 & $.039 * *$ & $.244 * *$ & $-.060 * *$ & $.047 * *$ & -.005 & $-.134 * *$ & $-.194 * *$ & $-.032 *$ & $-.056 * *$ & $-.300 * *$ & $.617 * *$ & $-.569 * *$ & $-.404 * *$ & $-.210 * *$ & $-.534 * *$ & $.666 * *$ & $-.417 * *$ & $.753 * *$ & - \\
\hline
\end{tabular}


International Journal of Child, Youth and Family Studies (2017) 8(1): 112-144

\section{Multivariate Analysis: Binge Drinkers vs. Non-binge Drinkers - Are There Differences?}

Due to concerns about sample size and power for the separate gender analyses, several variables that were not significantly correlated with binge drinking in either gender subsample were omitted from the multivariate analyses (positive mental health, negative affect, positive affect, social alienation, self-esteem, and having a family member with alcohol problems).

Table 5 Hierarchical Modelling Odds Ratios

\begin{tabular}{|c|c|c|c|}
\hline Predictor Variable & Model 1 & Model 2 & Model 3 (Full) \\
\hline & \multicolumn{3}{|c|}{ Male Sample } \\
\hline Not born in Canada & $.320 * *$ & $.380 *$ & .427 \\
\hline Live with parents & .935 & .879 & 1.02 \\
\hline GPA & 1.00 & 1.11 & 1.01 \\
\hline Risky sexual behavior & & $6.72 *$ & $6.42 *$ \\
\hline Other drug use & & .720 & .706 \\
\hline Cigarette use & & 2.95 & $3.61 *$ \\
\hline RAPI & & $3.80 * *$ & $4.25 * *$ \\
\hline Age at first intoxication & & .949 & 1.02 \\
\hline Religiosity & & & .980 \\
\hline Impulsivity & & & 1.03 \\
\hline Life satisfaction & & & $1.17 * *$ \\
\hline Depression & & & .996 \\
\hline Anxiety & & & .968 \\
\hline Cox \& Snell R² & .044 & .206 & .267 \\
\hline \multirow[t]{2}{*}{ Nagelkerke $\mathrm{R}^{2}$} & .061 & .287 & .371 \\
\hline & \multicolumn{3}{|c|}{ Female Sample } \\
\hline Not born in Canada & .644 & .751 & .964 \\
\hline Live with parents & 1.33 & 1.37 & 1.37 \\
\hline GPA & 1.02 & 1.12 & 1.10 \\
\hline Risky sexual behavior & & 1.05 & .871 \\
\hline Other drug use & & $1.96 *$ & 1.76 \\
\hline Cigarette use & & 1.51 & 1.44 \\
\hline RAPI & & $3.02 * *$ & $2.80 * *$ \\
\hline Age at first intoxication & & .967 & 1.01 \\
\hline Religiosity & & & $.961^{* *}$ \\
\hline Impulsivity & & & $1.04 * *$ \\
\hline Life satisfaction & & & 1.07 \\
\hline Depression & & & .985 \\
\hline Anxiety & & & 1.03 \\
\hline Cox \& Snell R 2 & .009 & .110 & .155 \\
\hline Nagelkerke $\mathrm{R}^{2}$ & .013 & .157 & .221 \\
\hline
\end{tabular}


International Journal of Child, Youth and Family Studies (2017) 8(1): 112-144

Although depression and anxiety are highly correlated in both male and female subsamples $(r>$.7), both variables were left in the model for conceptual consistency, since neither was significant, whether the other was removed or not, or whether combined into one index variable. Furthermore, variance inflation factor values below 2.5 and tolerance values near 1 indicated that collinearity was not a concern for any of the modelled variables (Allison, 1999). Logistic regression modelling (odds ratios are reported in Table 5) was conducted hierarchically, with sociodemographic variables entered first (Model 1), followed by the addition of behavioural variables (Model 2), and then dispositions and mental health variables (Model 3).

Table 6 Full Model (3) Logistic Regression Results

\begin{tabular}{|c|c|c|c|}
\hline Predictor Variable & $b$ (se) & Odds Ratio & $95 \%$ CI \\
\hline & \multicolumn{3}{|c|}{ Male Sample $(\mathrm{n}=180)$} \\
\hline Not born in Canada & $-.852(.534)$ & .427 & $.150-1.22$ \\
\hline Live with parents & $.019(.460)$ & 1.02 & $.414-2.51$ \\
\hline GPA & $.010(.460)$ & 1.01 & $.755-1.35$ \\
\hline Risky sexual behaviour & $1.86(.835)$ & 6.42 & $1.25-33.0 *$ \\
\hline Other drug use & $-.348(.465)$ & .706 & $.284-1.76$ \\
\hline Cigarette use & $1.28(.631)$ & 3.61 & $1.05-12.4^{*}$ \\
\hline RAPI & $1.45(.573)$ & 4.25 & $1.38-13.09 * *$ \\
\hline Age at first intoxication & $.018(.084)$ & 1.02 & $.864-1.20$ \\
\hline Religiosity & $-.021(.022)$ & .980 & $.938-1.02$ \\
\hline Impulsivity & $.025(.022)$ & 1.03 & $.981-1.07$ \\
\hline Life satisfaction & $.154(.061)$ & 1.17 & $1.03-1.31 * *$ \\
\hline Depression & $-.004(.036)$ & .996 & $.929-1.07$ \\
\hline \multirow[t]{2}{*}{ Anxiety } & $-.032(.057)$ & .968 & $.866-1.08$ \\
\hline & \multicolumn{3}{|c|}{ Female Sample $(\mathrm{n}=327)$} \\
\hline Not born in Canada & $-.036(.394)$ & .964 & $.445-2.09$ \\
\hline Live with parents & $.314(.303)$ & 1.37 & $.755-2.48$ \\
\hline GPA & $.099(.116)$ & 1.10 & $.880-1.38$ \\
\hline Risky sexual behaviour & $-.138(.611)$ & .871 & $.263-2.89$ \\
\hline Other drug use & $.565(.353)$ & 1.76 & $.880-3.52$ \\
\hline Cigarette use & $.361(.430)$ & 1.44 & $.618-3.34$ \\
\hline RAPI & $1.03(.415)$ & 2.80 & $1.24-6.31 * *$ \\
\hline Age at first intoxication & $.007(.078)$ & 1.01 & $.864-1.17$ \\
\hline Religiosity & $-.039(.015)$ & .961 & $.934-.990 * *$ \\
\hline Impulsivity & $.042(.016)$ & 1.04 & $1.01-1.08 * *$ \\
\hline Life satisfaction & $.069(.042)$ & 1.07 & $.987-1.16$ \\
\hline Depression & $-.015(.020)$ & .985 & $.947-1.02$ \\
\hline Anxiety & $.025(.034)$ & 1.03 & $.960-1.02$ \\
\hline
\end{tabular}

Note: pooled estimates ${ }^{*} p \leq .05 ; * * p \leq .01$ 
As reported in Table 6, after controlling for all other variables in the full model, only three variables were significantly related to binge drinking for females: having reported negative alcohol-related consequences in the past year, religiosity, and impulsivity. Of these three variables, only negative alcohol-related consequences was significantly associated with male binge drinking. Additionally, for males, having engaged in risky sexual behaviour, smoking cigarettes, and life satisfaction were significant correlates of binge drinking. Although being born outside Canada was negatively associated with binge drinking for males in the first two models, it became insignificant in Model 3 once dispositions and mental health variables were added. None of the other variables were significant for either gender at the multivariate level.

Binge drinkers were significantly more likely than non-binge drinkers (2.8 times for females, 4.25 times for males) to report higher scores on RAPI (i.e., a higher number of adverse alcohol-related consequences). In terms of gender differences, female binge drinkers (but not males) were significantly, albeit slightly, more likely to report higher levels of impulsivity than their non-binge drinking peers. In contrast, female binge drinkers (but again not males) were significantly, if modestly, less likely to report high levels of religiosity compared to non-binge drinkers. Male binge drinkers (but not females) were 3.6 times more likely than non-binge drinkers to smoke cigarettes and 6.4 times more likely to have engaged in risky sex. Finally, with regard to life satisfaction, male binge drinkers (but not females) reported higher scores on the life satisfaction index compared to non-binge drinkers.

\section{Discussion}

Although numerous studies have found that male university students are more likely to report binge drinking or heavy alcohol use compared to their female counterparts - previous Canadian studies included (Adlaf \& Gliksman, 2005; Balodis et al., 2009; Carlson et al., 2010) — the current investigation found that females were just as likely as males to report having engaged in binge drinking. Such results could be attributed in part to the use of a gender-specific binge drinking variable, and in part to changing trends in binge drinking among university students, particularly women (Counter, 2016). Delucchi et al. (2008) used an even more strongly genderweighted measure of five or more drinks for men and three or more drinks for women, and found that, among their sample, female students were more likely to engage in binge drinking than males. Regarding the social trend aspect, a meta-analysis of university alcohol consumption in Ireland and the United Kingdom conducted by Davoren et al. (2016) found that the gender gap between male and female university students is narrowing with regard to excessive alcohol consumption. Consistent with this, using American data from the National Survey on Drug Use and Health, with a non-gender-weighted binge drinking criterion of five drinks in one sitting, Grucza, Norberg, and Bierut (2009) found that rates of binge drinking have been on the rise in recent decades (19792006) for females aged 12 to 34, while male rates have decreased or remained steady. Likewise, another national survey in the U.S. (Johnston, O’Malley, Bachman, Schulenberg, \& Miech, 2016) found that the gender gap in college binge drinking (using a five-drink criterion for both sexes) 
decreased from 23 percentage points in 1975 to 4 points in 2015. In light of these trends, and the fact that the present study used a gender-weighted measure of binge drinking with a very recent university student sample, it does not seem surprising that the findings of the present study differ from those of older studies.

Living with parents, having a history of family alcohol problems, and GPA were not significant differentiators between binge and non-binge drinkers for either gender. Although previous Canadian studies have found that students who live on campus or away from their parents are more likely to report heavy drinking than are students who live off campus with their parents (e.g., Adlaf et al., 2005; Carlson et al., 2010), the results of the current research do not reflect such an association. It is worth noting that the large, party-oriented sororities or fraternities commonly found in the U.S. are far less prevalent in Canada, and therefore perhaps the difference between off-campus and on-campus life is less marked at some Canadian universities. This may be particularly true of the university sampled in the current study, which does not have a substantial student residential district or a hospitality and entertainment district on or near campus. This study was the first to test the relationship between history of family alcohol abuse and binge drinking in a Canadian sample of undergraduates; the results indicate no significant association, which is consistent with previous American studies (Baer, 2002; Engs, 1990).

With regard to participants' GPAs, the current results were inconsistent with the majority of the literature, including previous Canadian research (Gliksman et al., 1997). However, the GPA variable used in the present study was created using a mixture of high school averages and university GPAs, and therefore may not reflect recent university performance for some students still early in their first year at the time of survey administration. Finally, students born in Canada were more likely to report binge drinking than their peers who were not born in Canada, a finding consistent with previous Canadian literature on the general population (Ross, 1995); however, this difference became insignificant once mental health and dispositional variables in the model were controlled for. More Canadian research is required to explore patterns of alcohol use among international, immigrant, and Canadian-born university students.

Working from a developmental psychopathology perspective on emerging adulthood that focuses on the health risks associated with life transitions (Schulenberg \& Maggs, 2002; Schulenberg \& Zarrett, 2006), it was expected that binge drinking would be marked by greater cooccurrence of mental health problems; in actuality, almost none of the mental health variables in the present study differed between binge drinkers and non-binge drinkers for either gender. Despite other findings in the literature showing that anxiety and depression (Mushquash et al., 2013; Swendsen et al., 1998), positive and negative affect (Townshend \& Duka, 2005), and indicators of wellbeing such as self-esteem or social alienation (Mohamed \& Ajmal, 2015) are connected to binge drinking or alcohol use, no such associations were significant in the present sample of Canadian university students. For example, the current sample did not show any significant difference between binge and non-binge drinkers in degree of social alienation. However, as noted in the literature, socially alienated or lonely people (Knox et al., 2007), as well as people on the 
other end of the spectrum who have many friends or are subject to greater peer pressure (Talbott et al., 2008), have been found to be more likely to engage in heavy alcohol consumption. Mixed results have also been evident in relation to self-esteem, and there is empirical precedent for the current finding of no relationship between self-esteem and binge drinking (e.g., Luhtanen \& Crocker, 2005; Poikolainen et al., 2001).

Life satisfaction was significant in bivariate and multivariate analyses for males only; however, the relationship between life satisfaction and binge drinking was somewhat inconsistent with the literature, which generally indicates that binge drinkers are more likely to report lower levels of quality of life (Mohamed \& Ajmal, 2015). Among the current sample of university students, male binge drinkers were more likely to report higher life satisfaction (or quality of life) than non-binge drinkers, but no such difference was evident for females. Interestingly, there is some evidence to suggest alcohol consumption may be associated with positive social consequences (Nyström, 1992; Park, 2004) for university students, such as increased intimacy and self-disclosure in social interactions (Nezlek et al., 1994). In fact, Nezlek et al. (1994) suggest that some level of occasional binge drinking may actually be normative and is associated with fuller integration into the collegiate community compared to students who have too many, or no, episodes of binge drinking. The present findings seem in line with this possibility, at least for males, as many binge drinkers fell in the "once in the past 30 days" or " 1 to 2 times per week" frequency categories. Male students may be more apt to perceive some positive effects on life satisfaction with normative or occasional binge drinking, but these effects may dissipate with higher frequency of binge drinking, thus revealing a curvilinear relationship (Murphy, McDevittMurphy, \& Barnett, 2005).

In our findings, higher levels of religiosity were associated with a lower likelihood of binge drinking — but only for females. This is again somewhat consistent with the literature, including previous Canadian studies (e.g., Hundleby, 1987; Rasic et al., 2011). The association could be attributed to the fact that university students who report strong religious affiliation are more likely to be invested in religions that preach abstention from alcohol or moderation in its consumption, coupled with the higher levels of religious faith reported in the present sample by females than by males $(t=2.05, p<.05)$. The relationship between impulsivity and binge drinking was also only partially consistent with previous results in the Canadian literature (e.g., Carlson et al., 2010; Wellman et al., 2014), in that high levels of impulsivity were associated with binge drinking, but for females only. Explanations for such a relationship are largely based on neurological differences, with more impulsive people tending to exhibit less control over heavy alcohol use and less foresight regarding the consequences of consuming large amounts of alcohol. The present result is rather novel and should be reassessed in a larger sample, especially given the modest size of the male sample in the current study. The significant relationship between impulsivity and binge drinking found only among females in the current study could be related to the trend toward increased binge drinking among women, which, in turn, could be related to increasing deviance from traditional gender roles by women (Nolen-Hoeksema, 2004). Nolen-Hoeksema (2004) noted 
that alcohol consumption has often been related to male gender roles such as aggressiveness, while female gender roles such as nurturing tendencies have not been related to alcohol consumption. However, in recent times, women have begun to transcend the traditional gender roles, and therefore perhaps women who no longer embrace the traditional gender roles that support women as calm and nurturing rather than impulsive and aggressive are more likely to engage in binge drinking, while women who are less impulsive and more abiding of traditional gender roles are less likely to engage in binge drinking (see further discussion of gender roles and alcohol in NolenHoeksema, 2004).

Finally, risky sexual behaviour was significantly associated with binge drinking — but only for males. The definition of risky sexual behaviour in the present study is not rooted in a moral perspective, but a public health one positing that people under the influence of alcohol, both male and female, are more likely to engage in sexual behaviours (e.g., having unprotected sex, or sex with a partner of unknown sexual health status) that pose such risks as exposure to sexually transmitted infections. One explanation for the significant relationship between binge drinking and risky sexual behaviour among male participants, but not female participants, is found in Desiderato and Crawford (1993), who observed that female college students were more likely to have concerns about sexually transmitted diseases like AIDS than their male counterparts; this could suggest that it would be less likely for women, even those who engage in binge drinking, to engage in risky sexual behaviour. Finally, as found in Poulson, Eppler, Satterwhite, Wuensch, and Bass (1998), among female college students, strength of religious belief was negatively correlated with risky sexual behaviour and alcohol consumption, as is also the case in the present study. Therefore, any potential positive effect of binge drinking on risky sexual behaviour may be offset by the negative relationship between religious faith and both binge drinking and risky sexual behaviour among females (who as noted above reported higher average levels of religiosity than males).

Tobacco use and the use of illicit drugs (e.g., marijuana, heroin, and cocaine) were significant bivariate correlates of binge drinking, consistent with previous literature (Bennett et al., 1999; DiGrande et al., 2000); however, both variables were non-significant for females in the multivariate analysis, and only cigarette smoking remained significant for males. One explanation for this significant relationship among male participants, but not females, could be that one motive for cigarette use among women is physical attractiveness, whereas male smoking often derives from the urge to rebel socially, a motive also implicated in binge drinking (see Waldron, 1991). This explanation, rooted in traditional gender roles, suggests that women may be more attuned to smoking cigarettes independent of drinking, whereas for men smoking and drinking are more likely to be co-occurring activities. A somewhat similar relationship was seen for age at first alcohol intoxication, wherein individuals who reported a younger age of initial intoxication were significantly more likely to engage in binge drinking at the bivariate level, again consistent with the previous literature (e.g., Townshend et al., 2014), although the association was rendered insignificant at the multivariate level for both genders. RAPI was the only substance use indicator that remained significant at the multivariate level for both genders, with binge drinkers being 
International Journal of Child, Youth and Family Studies (2017) 8(1): 112-144

significantly more likely to report higher frequency of alcohol-related problems (such as not being able to complete homework or study for a test, getting into a fight, causing shame or embarrassment to someone, neglecting responsibilities, and missing a day of school or work), a finding consistent with previous Canadian literature (Carlson et al., 2010).

On the whole, the results of the current study are mixed in relation to the literature exploring binge drinking and its correlates among university students internationally, and in Canada in particular. However, with the exception of Carlson et al. (2010), previous Canadian studies of university students relied on data more than a decade old; it is likely that Canadian university students' alcohol consumption patterns have changed over this time. Additionally, the present study differs from, and complements, the Carlson et al. (2010) study in several ways. For example, we had a larger, more recent sample, and a very different set of variables in our model, with the Carlson study focusing on personality traits and the present study focusing on a number of mental health variables. In fact, the only non-demographic predictor common to the two studies is impulsivity. Additionally, the time frame for measuring binge drinking in the Carlson study was 12 months rather than 30 days as in the present study. Another recent Canadian study by Wellman and colleagues (2014) found that impulsivity, novelty-seeking, and subclinical depression were associated with sustained binge drinking among a sample of young adults. Their study also differs from the present one in a number of ways; for example, in addition to modelling different predictors, their sample was not specific to university students, and they did not use a genderweighted measure of binge drinking (they used five drinks or more as the cut-off for both sexes). Finally, the present study also differed from the latter two studies in that it ran separate logistic regression models for males and females.

\section{Limitations and Future Research}

The data used in this study are subject to the limitations of cross-sectional self-report surveys, and due caution should be exercised in generalizing from a single university sample to all Canadian university students. Also, given that the sample comprised mostly Introductory Sociology students, this sample may be more homogeneous in a number of respects than a general undergraduate sample; such reduced variability could have resulted in fewer significant associations between binge drinking and the other variables. Future research should assess these relationships in a more general university or post-secondary student population. Similarly, it is possible gender differences may have been more evident with a larger, more diverse sample. For example, drawing from additional faculties, including Engineering and Science, would likely result in a greater proportion of male participants.

It also bears noting that there may be associations between binge drinking and the mental health variables that went undetected due to our dichotomous (binge versus non-binge drinker) criterion variable. That is, the strength of the relationship between mental health and alcohol consumption may vary according to the level or frequency of binge drinking. In order to detect this difference, future research could employ multinomial or ordinal logistic regression to assess 
whether the associations differ according to frequency of binge drinking. Engaging in binge drinking almost every day in the previous 30 days is likely to impact an individual's life more than would be the case for someone only partaking in one heavy drinking episode during that time. Distinguishing between heavy, moderate, and occasional binge drinkers may therefore be particularly informative in identifying how severity of binge drinking is related to differences in mental health.

Further, students who engage in excessive alcohol consumption often do not see themselves as having an alcohol problem (Knight et al., 2002), misconceive the average amount of alcohol that a university student consumes (Arbour-Nicitopoulos et al., 2010; Perkins, 2007), or think binge drinking involves drinking more than just five alcoholic beverages for males and four for females (Wechsler \& Kuo, 2000). Another way to gauge the extent of heavy alcohol consumption would be to use the number and severity of alcohol-related problems as the criterion variable. Measures such as the frequency of binge drinking and the severity and frequency of alcohol problems could provide a more detailed indication of unhealthy or excessive alcohol use and its correlates among Canadian university students. For example, Paljärvi and colleagues (2009) used indicators of binge-drinking severity and found that only heavy binge drinking (binge drinking patterns that involved intoxication, passing out, and being hung over) was associated with depression. It would also be useful to include measures of motives for drinking, such as positive reinforcement motivation (e.g., sensation seeking) and negative reinforcement motivation (e.g., anxiety sensitivity, hopelessness) as described by Woicik, Stewart, Pihl, and Conrod (2009), as well as normative perceptions about alcohol consumption (Chauvin, 2011; Crawford \& Novak, 2010). Finally, to our knowledge, there has been no longitudinal study of the relationship between binge drinking and its correlates among Canadian university students. Such a study would undoubtedly contribute much to our understanding of the temporal ordering of relationships between binge drinking and its correlates.

\section{Conclusion}

In summary, the present study found no gender differences in the prevalence of binge drinking, but there were several gender differences in the correlates of binge drinking. In light of much of the existing Canadian and international literature, a number of the current findings are rather novel: (a) no association between binge drinking and depression or anxiety, (b) gender differences such as greater reported life satisfaction for male (but not female) binge drinkers compared to non-binge drinkers, (c) greater probability of smoking cigarettes and engaging in risky sex for male (but not female) binge drinkers, (d) greater impulsivity for female (but not male) binge drinkers, and (e) lower religiosity for female (but not male) binge drinkers. Interestingly, although binge drinkers in this sample, on average, reported significantly more alcohol-related problems, these did not seem to manifest in greater mental health problems. It may be that there are mental health correlates of binge drinking that are undetected in the present study due to the relative homogeneity of the sample and the use of a dichotomous binge drinking criterion variable. 
International Journal of Child, Youth and Family Studies (2017) 8(1): 112-144

Follow-up research would benefit from a more graduated indicator of binge drinking, such as frequency and intensity of binge drinking, and a larger, more representative Canadian university student sample, ideally with repeated measures across time. Such research is required to increase understanding of risk and protective factors for heavy alcohol consumption among university students, and how best to mitigate the risk factors, enhance the protective factors, and promote healthy living among a population of young adults seeking to embark on a productive, prosperous, and happy life.

\section{Acknowledgement}

Collection of the SLWBS data used in this study was funded by the Manitoba Gambling Research Program of Manitoba Liquor and Lotteries; however, the findings and conclusions of this paper are those solely of the authors and do not necessarily represent the views of Manitoba Liquor and Lotteries. 
International Journal of Child, Youth and Family Studies (2017) 8(1): 112-144

\section{References}

Adlaf , E., Gliksman, L., Demers, A., \& Newton-Taylor, B. (2001). The prevalence of elevated psychological distress among Canadian undergraduates: Findings from the 1998 Canadian Campus Survey. Journal of American College Health, 50(2), 67-72. doi:10.1080/07448480109596009

Adlaf, E., Demers, A., \& Gliksman, L. (Eds). (2005). Canadian campus survey 2004. Toronto, ON: Centre for Addiction and Mental Health.

Allison, P.D. (1999). Multiple regression: A primer. Thousand Oaks, CA: Pine Forge Press.

Arbour-Nicitopoulos, K. P., Kwan, M. Y., Lowe, D., Taman, S., \& Faulkner, G. E. (2010). Social norms of alcohol, smoking, and marijuana use within a Canadian university setting. Journal of American College Health, 59(3), 191-196. doi:10.1080/07448481.2010.502194

Arnett, J. J. (2005). The developmental context of substance use in emerging adulthood. Journal of Drug Issues, 35, 235-254. doi:10.1177/002204260503500202

Baer, J. S. (2002). Student factors: Understanding individual variation in college drinking. Journal of Studies on Alcohol, 14(Suppl.), 40-53. doi:10.15288/jsas.2002.s14.40

Balodis, I. M., Potenza, M. N., \& Olmstead, M. C. (2009). Binge drinking in undergraduates: Relationships with gender, drinking behaviors, impulsivity and the perceived effects of alcohol. Behavioural Pharmacology, 20(5-6), 518-526.

doi:10.1097/FBP.0b013e328330c779

Bennett, M. E., Miller, J. H., \& Woodall, W. G. (1999). Drinking, binge drinking, and other drug use among southwestern undergraduates: Three-year trends. The American Journal of Drug and Alcohol Abuse, 25(2), 331-350. doi:10.1081/ADA-100101864

Bersamin, M. M., Paschall, M. J., Saltz, R. F., \& Zamboanga, B. L. (2012). Young adults and casual sex: The relevance of college drinking settings. Journal of Sex Research, 49(2-3), 274-281. doi:10.1080/00224499.2010.548012

Bock, E. W., Cochran, J. K., \& Beeghley, L. (1987). Moral messages: The relative influence of denomination on the religiosity-alcohol relationship. Sociological Quarterly,28, 89-103. Retrieved from http://www.jstor.org/stable/4121422

Brown, J. L., \& Vanable, P. A. (2007). Alcohol use, partner type, and risky sexual behavior among college students: Findings from an event-level study. Addictive Behaviors, 32(12), 2940-2952. doi:10.1016/j.addbeh.2007.06.011 
International Journal of Child, Youth and Family Studies (2017) 8(1): 112-144

Caamaño-Isorna, F., Corral, M., Parada, M., \& Cadaveira, F. (2008). Factors associated with risky consumption and heavy episodic drinking among Spanish university students. Journal of Studies on Alcohol and Drugs, 69(2), 308-312. doi:10.15288/jsad.2008.69.308

Caetano, R., Clark, C. L., \& Tam, T. (1998). Alcohol consumption among racial/ethnic minorities: Theory and research. Alcohol Research and Health, 22(4), 233-241.

Carlson, S. R., Johnson, S. C., \& Jacobs, P. C. (2010). Disinhibited characteristics and binge drinking among university student drinkers. Addictive Behaviors, 35(3), 242-251. doi:10.1016/j.addbeh.2009.10.020

Caswell, A. J., Celio, M. A., Morgan, M. J., \& Duka, T. (2016). Impulsivity as a multifaceted construct related to excessive drinking among UK students. Alcohol and Alcoholism, 51(1), 77-83. doi:10.1093/alcalc/agv070

Chauvin, C. D. (2011). Social norms and motivations associated with college binge drinking. Sociological Inquiry, 82(2), 257-281. doi:10.1111/j.1475-682X.2011.00400.x

Clark, A., Tran, C., Weiss, A., Caselli, G., Nikčević, A. V., \& Spada, M. M. (2012). Personality and alcohol metacognitions as predictors of weekly levels of alcohol use in binge drinking university students. Addictive Behaviors, 37(4), 537-540.

doi:10.1016/j.addbeh.2011.11.035

Conley, C. S., Kirsch, A., Dickson, D. A., \& Bryant, F. B. (2014). Negotiating the transition to college: Developmental patterns and gender differences in psychological functioning, cognitive-affective strategies, and social well-being. Emerging Adulthood, 2, 195-210. doi:10.1177/2167696814521808

Connor, J., Psutka, R., Cousins, K., Gray, A., \& Kypri, K. (2013). Risky drinking, risky sex: A national study of New Zealand university students. Alcoholism: Clinical and Experimental Research, 37(11), 1971-1978. doi:10.1111/acer.12175

Counter, R. (2016, February). When ladies love their liquor. Maclean's. Retrieved from http://www.macleans.ca/society/life/the-alarming-rise-in-binge-drinking-among-youngwomen/

Crawford, L. A., \& Novak, K. B. (2010). Beliefs about alcohol and the college experience as moderators of the effects of perceived drinking norms on student alcohol use. Journal of Alcohol and Drug Education, 54(3): 69-86. Retrieved from http://digitalcommons.butler.edu/facsch_papers/390

D’Alessio, M., Baiocco, R., \& Laghi, F. (2006). The problem of binge drinking among Italian university students: A preliminary investigation. Addictive Behaviors, 31(12), 2328-2333. doi:10.1016/j.addbeh.2006.03.002 
International Journal of Child, Youth and Family Studies (2017) 8(1): 112-144

Davoren, M. P., Demant, J., Shiely, F., \& Perry, I. J. (2016). Alcohol consumption among university students in Ireland and the United Kingdom from 2002 to 2014: A systematic review. BMC Public Health, 16, 173. doi:10.1186/s12889-016-2843-1

Delucchi, K. L., Matzger, H., \& Weisner, C. (2008). Alcohol in emerging adulthood: 7-year study of problem and dependent drinkers. Addictive Behaviors, 33(1), 134-142. doi:10.1016/j.addbeh.2007.04.027

Desiderato, L. L., \& Crawford, H. J. (1995). Risky sexual behavior in college students: Relationships between number of sexual partners, disclosure of previous risky behavior, and alcohol use. Journal of Youth and Adolescence, 24(1), 55-68. doi:10.1007/BF01537560

Deykin, E. Y., Levy, J. C., \& Wells, V. (1987). Adolescent depression, alcohol and drug abuse. American Journal of Public Health, 77(2), 178-182. doi:10.2105/AJPH.77.2.178

Diener, E. D., Emmons, R. A., Larsen, R. J., \& Griffin, S. (1985). The satisfaction with life scale. Journal of Personality Assessment, 49(1), 71-75. doi:10.1207/s15327752jpa4901_13

DiGrande, L., Perrier, M. P., Lauro, M. G., \& Contu, P. (2000). Alcohol use and correlates of binge drinking among university students on the Island of Sardinia, Italy. Substance Use \& Misuse, 35(10), 1471-1483. doi:10.3109/10826080009148226

Eaton, W. W., Smith, C., Ybarra, M., Muntaner, C., \& Tien, A. (2004). Center for Epidemiologic Studies Depression Scale: Review and revision (CESD and CESD-R). In M. E. Maruish (Ed.), The use of psychological testing for treatment planning and outcomes assessment: Instruments for adults (3rd ed., Vol. 3, pp. 363-377). Mahwah, NJ: Lawrence Erlbaum Associates.

Ebesutani, C., Regan, J., Smith, A., Reise, S., Higa-McMillan, C., \& Chorpita, B. F. (2012). The 10-item positive and negative affect schedule for children, child and parent shortened versions: Application of item response theory for more efficient assessment. Journal of Psychopathology and Behavioral Assessment, 34(2), 191-203. doi:10.1007/s10862-011$\underline{9273-2}$

Engs, R. C. (1990). Family background of alcohol abuse and its relationship to alcohol consumption among college students: An unexpected finding. Journal of Studies on Alcohol, 51(6), 542-547. doi:10.15288/jsa.1990.51.542

Fenzel, L. M. (2005). Multivariate analyses of predictors of heavy episodic drinking and drinking-related problems among college students. Journal of College Student Development, 46(2), 126-140. doi:10.1353/csd.2005.0013 
International Journal of Child, Youth and Family Studies (2017) 8(1): 112-144

Galen, L. W., \& Rogers, W. M. (2004). Religiosity, alcohol expectancies, drinking motives and their interaction in the prediction of drinking among college students. Journal of Studies on Alcohol, 65(4), 469-476. doi:10.15288/jsa.2004.65.469

Gibson, C., Schreck, C., \& Miller, M. (2004). Binge drinking and negative alcohol-related behaviors: A test of self-control theory. Journal of Criminal Justice, 32, 411-420. doi:10.1016/j.jcrimjus.2004.06.003

Gilbert, J. (2014). The effects of drinking on university grades: Does academic motivation play a role? Undergraduate Honors Theses [Paper 7]. University of Western Ontario. Retrieved from http://ir.lib.uwo.ca/psychd_uht/7/

Gliksman, L., Adlaf, E. M., Demers, A., \& Newton-Taylor, B. (2003). Heavy drinking on Canadian campuses. Canadian Journal of Public Health/Revue Canadienne de Santé Publique, 91(1), 17-21. doi:10.3109/09687639709017409

Gliksman, L., Newton-Taylor, B., Adlaf, E., \& Giesbrecht, N. (1997). Alcohol and other drug use by Ontario university students: The roles of gender, age, year of study, academic grades, place of residence and programme of study [1]. Drugs: Education, Prevention and Policy, 4(2), 117-129. doi:10.3109/09687639709017409

Grucza, R. A., Norberg, K. E., \& Bierut, L. J. (2009). Binge drinking among youths and young adults in the United States: 1979-2006. Journal of the American Academy of Child and Adolescent Psychiatry, 48, 692-702. doi:10.1097/CHI.0b013e3181a2b32f

Henges, A. L., \& Marczinski, C. A. (2012). Impulsivity and alcohol consumption in young social drinkers. Addictive Behaviors, 37(2), 217-220. doi:10.1016/j.addbeh.2011.09.013

Hundleby, J. D. (1987). Adolescent drug use in a behavioral matrix: A confirmation and comparison of the sexes. Addictive Behaviors, 12(2), 103-112.

Jessor, R., Costa, F. M., Krueger, P. M., \& Turbin, M. S. (2006). A developmental study of heavy episodic drinking among college students: The role of psychosocial and behavioral protective and risk factors. Journal of Studies on Alcohol, 67(1), 86-94. doi:10.15288/jsa.2006.67.86

Jessor, R., \& Jessor, S. L. (1977). Problem behavior and psychosocial development: A longitudinal study of youth. Cambridge, MA: Academic Press.

Johnston, L. D., O’Malley, P. M., Bachman, J. G., Schulenberg, J. E. \& Miech, R. A. (2016). Monitoring the future: National survey results on drug use, 1975-2015 (Vol. 2, College students and adults ages 19-55). Ann Arbor, MI: Institute for Social Research, The University of Michigan. 
International Journal of Child, Youth and Family Studies (2017) 8(1): 112-144

Keyes, C. L. (2009). Brief description of the mental health continuum short form (MHC-SF). Atlanta, GA: Emory University.

Knight, J. R., Wechsler, H., Kuo, M., Seibring, M., Weitzman, E. R., \& Schuckit, M. A. (2002). Alcohol abuse and dependence among US college students. Journal of Studies on Alcohol, 63(3), 263-270. doi:10.15288/jsa.2002.63.263

Knox, D., Vail-Smith, K., \& Zusman, M. (2007). The lonely college male. International Journal of Men's Health, 6(3), 273-279. doi:10.3149/jmh.0603.273

Kuo, M., Adlaf, E. M., Lee, H., Gliksman, L., Demers, A., \& Wechsler, H. (2002). More Canadian students drink but American students drink more: Comparing college alcohol use in two countries. Addiction, 97(12), 1583-1592. doi:10.1046/j.1360-0443.2002.00240.x

Kwan, M. Y., Faulkner, G. E., Arbour-Nicitopoulos, K. P., \& Cairney, J. (2013). Prevalence of health-risk behaviours among Canadian post-secondary students: Descriptive results from the National College Health Assessment. BMC Public Health, 13, 548. doi:10.1186/14712458-13-548

Kypri, K., Paschall, M. J., Langley, J., Baxter, J., Cashell- Smith, M., \& Bourdeau, B. (2009). Drinking and alcohol- related harm among New Zealand university students: Findings from a national web- based survey. Alcoholism: Clinical and Experimental Research, 33(2), 307-314. doi:10.1111/j.1530-0277.2008.00834.x

López-Caneda, E., Holguín, S. R., Corral, M., Doallo, S., \& Cadaveira, F. (2014). Evolution of the binge drinking pattern in college students: Neurophysiological correlates. Alcohol, 48(5), 407-418. doi:10.1016/j.alcohol.2014.01.009

Luhtanen, R. K., \& Crocker, J. (2005). Alcohol use in college students: Effects of level of selfesteem, narcissism, and contingencies of self-worth. Psychology of Addictive Behaviors, 19(1), 99-103. doi:10.1037/0893-164X.19.1.99

Martin-Albo, J., Núñez, J. L., Navarro, J. G., \& Grijalvo, F. (2007). The Rosenberg Self-Esteem Scale: Translation and validation in university students. The Spanish Journal of Psychology, 10(2), 458-467. doi:10.1017/S1138741600006727

Meyerhoff, D. J., Blumenfeld, R., Truran, D., Lindgren, J., Flenniken, D., Cardenas, V., ... \& Weiner, M. W. (2004). Effects of heavy drinking, binge drinking, and family history of alcoholism on regional brain metabolites. Alcoholism: Clinical and Experimental Research, 28(4), 650-661. doi:10.1097/01.ALC.0000121805.12350.CA

Mohamed, S., \& Ajmal, M. (2015). Multivariate analysis of binge drinking in young adult population: Data analysis of the 2007 Survey of Lifestyle, Attitude and Nutrition in Ireland. Psychiatry and Clinical Neurosciences, 69(8), 483-488. doi:10.1111/pcn.12284 
International Journal of Child, Youth and Family Studies (2017) 8(1): 112-144

Murphy, J. G., McDevitt-Murphy, M. E., \& Barnett, N. P. (2005). Drink and be merry? Gender, life satisfaction, and alcohol consumption among college students. Psychology of Addictive Behaviors, 19(2), 184-91. doi:10.1037/0893-164X.19.2.184

Mushquash, A. R., Stewart, S. H., Sherry, S. B., Sherry, D. L., Mushquash, C. J., \& MacKinnon, A. L. (2013). Depressive symptoms are a vulnerability factor for heavy episodic drinking: A short-term, four-wave longitudinal study of undergraduate women. Addictive Behaviors, 38(5), 2180-2186. doi:10.1016/j.addbeh.2012.11.008

National Institute on Alcohol Abuse and Alcoholism (NIAAA). (2003). Recommended alcohol questions. Retrieved from http://www.niaaa.nih.gov.uml.idm.oclc.org/research/guidelinesand-resources/recommended-alcohol-questions

National Institute of Alcohol Abuse and Alcoholism (NIAAA). (2004). NIAAA council approves definition of binge drinking. NIAAA Newsletter, 3, 3. Retrieved from https://pubs.niaaa.nih.gov/publications/Newsletter/winter2004/Newsletter_Number3.pdf

Nezlek, J. B., Pilkington, C. J., \& Bilbro, K. G. (1994). Moderation in excess: binge drinking and social interaction among college students. Journal of Studies on Alcohol, 55(3), 342-351. doi:10.15288/jsa.1994.55.342

Nolen-Hoeksema, S. (2004). Gender differences in risk factors and consequences for alcohol use and problems. Clinical Psychology Review, 24(8), 981-1010. doi:10.1016/j.cpr.2004.08.003

Nyström, M. (1992). Positive and negative consequences of alcohol drinking among young university students in Finland. British Journal of Addiction, 87, 715-722. doi:10.1111/j.1360-0443.1992.tb02717.x

Orchowski, L. M., Mastroleo, N. R., \& Borsari, B. (2012). Correlates of alcohol-related regretted sex among college students. Psychology of Addictive Behaviors, 26(4), 782-790. doi:10.1037/a0027840

Paljärvi, T., Koskenvuo, M., Poikolainen, K., Kauhanen, J., Sillanmäki, L. and Mäkelä, P. (2009). Binge drinking and depressive symptoms: A 5-year population-based cohort study. Addiction, 104, 1168-1178. doi:10.1111/j.1360-0443.2009.02577.x

Parada, M., Corral, M., Mota, N., Crego, A., Holguín, S. R., \& Cadaveira, F. (2012). Executive functioning and alcohol binge drinking in university students. Addictive Behaviors, 37(2), 167-172. doi:10.1016/j.addbeh.2011.09.015

Park, C. L. (2004). Positive and negative consequences of alcohol consumption in college students. Addictive Behaviors, 29, 311-321. doi:10.1016/j.addbeh.2003.08.006 
International Journal of Child, Youth and Family Studies (2017) 8(1): 112-144

Pascarella, E. T., Goodman, K. M., Seifert, T. A., Tagliapietra-Nicoli, G., Park, S., \& Whitt, E. J. (2007). College student binge drinking and academic achievement: A longitudinal replication and extension. Journal of College Student Development, 48(6), 715-727. doi:10.1353/csd.2007.0060

Patock-Peckham, J. A., Hutchinson, G. T., Cheong, J., \& Nagoshi, C. T. (1998). Effect of religion and religiosity on alcohol use in a college student sample. Drug and Alcohol Dependence, 49(2), 81-88. doi:10.1016/S0376-8716(97)00142-7

Perkins, H. W. (2007). Misperceptions of peer drinking norms in Canada: Another look at the "reign of error" and its consequences among college students. Addictive Behaviors, 32(11), 2645-2656. doi:10.1016/j.addbeh.2007.07.007

Perkins, H., \& Berkowitz, A. D. (1991). Collegiate COAs and alcohol abuse: Problem drinking in relation to assessments of parent and grandparent alcoholism. Journal of Counseling \& Development, 69(3), 237-240. doi:10.1002/j.1556-6676.1991.tb01495.x

Plante, T. G., \& Boccaccini, M. (1997). Reliability and validity of the Santa Clara strength of religious faith questionnaire. Pastoral Psychology, 45(6), 429-437. doi:10.1007/BF02310643

Poikolainen, K., Tuulio-Henriksson, A., Aalto-Setälä, T., Marttunen, M., \& Lönnqvist, J. (2001). Predictors of alcohol intake and heavy drinking in early adulthood: A 5-year follow-up of 15-19-year-old Finnish adolescents. Alcohol and Alcoholism, 36(1), 85-88. doi:10.1093/alcalc/36.1.85

Poulson, R. L., Eppler, M. A., Satterwhite, T. N., Wuensch, K. L., \& Bass, L. A. (1998). Alcohol consumption, strength of religious beliefs, and risky sexual behavior in college students. Journal of American College Health, 46(5), 227-232. doi:10.1080/07448489809600227

Powers, J., Duffy, L., Burns, L., \& Loxton, D. (2016). Binge drinking and subsequent depressive symptoms in young women in Australia. Drug and Alcohol Dependence, 161, 86-94. doi:10.1016/j.drugalcdep.2016.01.019

Pullen, L. M. (1994). The relationships among alcohol abuse in college students and selected psychological/demographic variables. Journal of Alcohol and Drug Education, 40(1), 3650 .

Rasic, D., Kisely, S., \& Langille, D. B. (2011). Protective associations of importance of religion and frequency of service attendance with depression risk, suicidal behaviours and substance use in adolescents in Nova Scotia, Canada. Journal of Affective Disorders, 132(3), 389-395. doi:10.1016/j.jad.2011.03.007 
International Journal of Child, Youth and Family Studies (2017) 8(1): 112-144

Ross, H. E. (1995). DSM-III-R alcohol abuse and dependence and psychiatric comorbidity in Ontario: Results from the Mental Health Supplement to the Ontario Health Survey. Drug and Alcohol Dependence, 39(2), 111-128. doi:10.1016/0376-8716(95)01150-W

Schaffer, M., Jeglic, E. L., \& Stanley, B. (2008). The relationship between suicidal behavior, ideation, and binge drinking among college students. Archives of Suicide Research, 12(2), 124-132. doi:10.1080/13811110701857111

Schoenborn, C. A., Stommel, M., \& Ward, B. W. (2014). Mortality risks associated with average drinking level and episodic heavy drinking. Substance Use \& Misuse, 49(10), 1250-1258. doi:10.3109/10826084.2014.891620

Schulenberg, J. E., \& Maggs, J. L. (2002). A developmental perspective on alcohol use and heavy drinking during adolescence and the transition to young adulthood. Journal of Alcohol Studies, 14(Suppl.), 54-70. doi:10.15288/jsas.2002.s14.54

Schulenberg, J. E., \& Zarrett, N. R. (2006). Mental health during emerging adulthood: Continuity and discontinuity in courses, causes, and functions. In J. J. Arnett \& J. L. Tanner (Eds.), Emerging adults in America: Coming of age in the 21st century (pp. 135-72). Washington, DC: American Psychological Association.

Simons, J. S., Christopher, M. S., \& Mclaury, A. E. (2004). Personal strivings, binge drinking, and alcohol-related problems. Addictive Behaviors, 29(4), 773-779.

doi:10.1016/j.addbeh.2004.02.006

Spitzer, R. L., Kroenke, K., Williams, J. B., \& Löwe, B. (2006). A brief measure for assessing generalized anxiety disorder: The GAD-7. Archives of Internal Medicine, 166(10), 10921097. doi:10.1001/archinte.166.10.1092

Stanford, M. S., Mathias, C. W., Dougherty, D. M., Lake, S. L., Anderson, N. E., \& Patton, J. H. (2009). Fifty years of the Barratt Impulsiveness Scale: An update and review. Personality and Individual Differences, 47(5), 385-395. doi:10.1016/j.paid.2009.04.008

Statistics Canada. (2015). Heavy drinking, 2014 (Health Fact Sheets, 82-625-X). Ottawa, ON: Author. Retrieved from http://www.statcan.gc.ca/pub/82-625-x/2015001/article/14183eng.htm

Swendsen, J. D., Merikangas, K. R., Canino, G. J., Kessler, R. C., Rubio-Stipec, M., \& Angst, J. (1998). The comorbidity of alcoholism with anxiety and depressive disorders in four geographic communities. Comprehensive Psychiatry, 39(4), 176-184. doi:10.1016/S0010$\underline{440 X(98) 90058-X}$

Tabachnick, B., \& Fidell, L. (2013). Using multivariate statistics (6th ed.). Boston, MA: Pearson Education. 
International Journal of Child, Youth and Family Studies (2017) 8(1): 112-144

Talbott, L. L., Martin, R. J., Usdan, S. L., Leeper, J. D., Umstattd, M. R., Cremeens, J. L., \& Geiger, B. F. (2008). Drinking likelihood, alcohol problems, and peer influence among firstyear college students. The American Journal of Drug and Alcohol Abuse, 34(4), 433-440. doi:10.1080/00952990802122655

Tavolacci, M. P., Boerg, E., Richard, L., Meyrignac, G., Dechelotte, P., \& Ladner, J. (2016). Prevalence of binge drinking and associated behaviours among 3286 college students in France. BMC Public Health, 16, 1. doi:10.1186/s12889-016-2863-X

Townshend, J. M., \& Duka, T. (2005). Binge drinking, cognitive performance and mood in a population of young social drinkers. Alcoholism: Clinical and Experimental Research, 29(3), 317-325. doi:10.1097/01.ALC.0000156453.05028.F5

Townshend, J. M., Kambouropoulos, N., Griffin, A., Hunt, F. J., \& Milani, R. M. (2014). Binge drinking, reflection impulsivity, and unplanned sexual behavior: Impaired decision- making in young social drinkers. Alcoholism: Clinical and Experimental Research, 38(4), 11431150. doi:10.1111/acer.12333

Vaez, M., \& Laflamme, L. (2003). Health behaviors, self-rated health, and quality of life: A study among first-year Swedish university students. Journal of American College Health, 51(4), 156-162. doi:10.1080/07448480309596344

Valliant, P. M., \& Scanlan, P. (1996). Personality, living arrangements, and alcohol use by first year university students. Social Behavior and Personality: An International Journal, 24(2), 151-156. doi:10.2224/sbp.1996.24.2.151

Waldron, I. (1991). Patterns and causes of gender differences in smoking. Social Science \& Medicine, 32(9), 989-1005. doi:10.1016/0277-9536(91)90157-8

Wechsler, H., Molnar, B. E., Davenport, A. E., \& Baer, J. S. (1999). College alcohol use: A full or empty glass?. Journal of American College Health, 47(6), 247-252. doi:10.1080/07448489909595655

Wechsler, H., \& Kuo, M. (2000). College students define binge drinking and estimate its prevalence: Results of a national survey. Journal of American College Health, 49(2), 57-64. doi:10.1080/07448480009596285

Wechsler, H., Dowdall, G. W., Davenport, A., \& Rimm, E. B. (1995). A gender-specific measure of binge drinking among college students. American Journal of Public Health, 85(7), 982985.

Weitzman, E. R., Nelson, T. F., \& Wechsler, H. (2003). Taking up binge drinking in college: The influences of person, social group, and environment. Journal of Adolescent Health, 32(1), 26-35. doi:10.1016/S1054-139X(02)00457-3 
International Journal of Child, Youth and Family Studies (2017) 8(1): 112-144

Wellman, R. J., Contreras, G. A., Dugas, E. N., O’Loughlin, E. K., \& O’Loughlin, J. L. (2014). Determinants of sustained binge drinking in young adults. Alcoholism: Clinical and Experimental Research, 38(5), 1409-1415. doi:10.1111/acer.12365

Wells, G. M. (2010). The effect of religiosity and campus alcohol culture on collegiate alcohol consumption. Journal of American College Health, 58(4), 295-304. doi:10.1080/07448480903380250

White, H. R., \& Labouvie, E. W. (2000). Longitudinal trends in problem drinking as measured by the Rutgers Alcohol Problem Index. Alcoholism: Clinical and Experimental Research, 24(5 Suppl. 1).

Woicik, P.A., Stewart, S. H., Pihl, R.O., \& Conrod P. J. (2009). The Substance Use Risk Profile Scale: A scale measuring traits linked to reinforcement-specific substance use profiles. Addictive Behaviors, 34, 1042-1055. doi:10.1016/j.addbeh.2009.07.001 